\title{
On the Generalized Hyers-Ulam Stability of a Functional Equation and Its Consequences
}

\author{
Krzysztof Ciepliński®i
}

\begin{abstract}
The aim of this note is to show the generalized Hyers-Ulam stability of a functional equation in four variables. In order to do this, the fixed point method is applied. As corollaries from our main result, some outcomes on the stability of some known equations will be also derived.
\end{abstract}

Mathematics Subject Classification. 39B82, 47H10.

Keywords. Hyers-Ulam stability, functional equation, fixed point method, bi-quadratic mapping.

\section{Introduction}

The question about an error one commits replacing an object possessing some properties by an object fulfilling them only approximately is natural both in mathematics and in many other scientific investigations. One of the effective approaches to deal with it is using the notion of the generalized Hyers-Ulam stability.

Let us recall that an equation is said to be Hyers-Ulam stable in a class of mappings if each mapping from this class satisfying our equation "approximately" is "near" to its actual solution.

It is well-known that the problem of the stability of homomorphisms of metric groups or, in other words, of the Cauchy functional equation was posed by S.M. Ulam in 1940. A year later, Hyers in [22] gave its solution in the case of Banach spaces. 
In recent years, the Hyers-Ulam stability of several objects (for instance functional equations and inequalities, isometries, differential, difference, integral and integro-differential equations, flows, groups, vector measures, and $C^{*}$ algebras) has been studied by many researchers (for more information on this notion as well as its applications we refer the reader to papers $[1-3,5,8,9,12-$ $14,16,18-20,24-26,30]$ and books $[7,23])$.

Assume that $X$ is a linear space over the field $\mathbb{F}$, and $Y$ is a linear space over the field $\mathbb{K}$. Let, moreover, $a_{1}, a_{2}, a_{3}, a_{4}, b_{1}, b_{2}, b_{3}, b_{4} \in \mathbb{F}$ and $C_{11}$, $C_{12}, C_{21}, C_{22} \in \mathbb{K}$ be given scalars.

In this note, we deal with the generalized, in the spirit of Bourgin (see [4]), Hyers-Ulam stability of the following functional equation in four variables:

$$
\begin{aligned}
& f\left(a_{1}\left(x_{1}+x_{2}\right), b_{1}\left(y_{1}+y_{2}\right)\right)+f\left(a_{2}\left(x_{1}+x_{2}\right), b_{2}\left(y_{1}-y_{2}\right)\right) \\
& \quad+f\left(a_{3}\left(x_{1}-x_{2}\right), b_{3}\left(y_{1}+y_{2}\right)\right)+f\left(a_{4}\left(x_{1}-x_{2}\right), b_{4}\left(y_{1}-y_{2}\right)\right) \\
& =C_{11} f\left(x_{1}, y_{1}\right)+C_{12} f\left(x_{1}, y_{2}\right)+C_{21} f\left(x_{2}, y_{1}\right)+C_{22} f\left(x_{2}, y_{2}\right),
\end{aligned}
$$

where $f: X^{2} \rightarrow Y$ and $x_{1}, x_{2}, y_{1}, y_{2} \in X$.

In order to do this, we use a variant of the fixed point method (more information about this method as well as the interplay between the fixed point theory and the Hyers-Ulam stability one can find in survey papers $[6,10])$, namely we apply a fixed point result of Diaz and Margolis from [15] (let us only mention here that other approaches to proving the stability of functional equations include the Hyers/direct method (see [22]), the method of invariant means (see [31]), the method based on sandwich theorems (see [27]), and the method using the concept of shadowing (see [32])).

As corollaries from our main result (Theorem 2), some outcomes on the stability of some known equations will be derived in Sect. 3. Moreover, we generalize the main result from [11].

Denote by $\mathbb{N}$, as usual, the set of all positive integers, put $\mathbb{N}_{0}:=\mathbb{N} \cup\{0\}$ and

$$
C:=C_{11}+C_{12}+C_{21}+C_{22} \text {. }
$$

Assume, moreover, that $C \neq 0$.

\section{Main Result}

In this section, we prove the generalized Hyers-Ulam stability of functional equation (1).

Before we do this, let us recall that a pair $(G, d)$ such that $G$ is a nonempty set and $d: G \times G \rightarrow[0, \infty]$ is a function satisfying the standard metric axioms is called a generalized metric space.

The below result from [15] plays a crucial role in the proof of the main result of this note. 
Proposition 1. Assume that $(\mathcal{G}, d)$ is a complete generalized metric space and $T: \mathcal{G} \rightarrow \mathcal{G}$ is a strictly contractive operator with the Lipschitz constant $L<1$. If there are $n_{0} \in \mathbb{N}_{0}$ and $x \in \mathcal{G}$ such that $d\left(T^{n_{0}+1} x, T^{n_{0}} x\right)<\infty$, then:

(i) the sequence $\left(T^{j} x\right)_{j \in \mathbb{N}}$ is convergent, and its limit $x^{*}$ is a fixed point of the operator $T$;

(ii) $x^{*}$ is the unique fixed point of $T$ in the set

$$
\mathcal{G}^{*}:=\left\{y \in \mathcal{G}: d\left(T^{n_{0}} x, y\right)<\infty\right\} ;
$$

(iii) if $y \in \mathcal{G}^{*}$, then

$$
d\left(y, x^{*}\right) \leq \frac{1}{1-L} d(T y, y)
$$

Our main result is the following.

Theorem 2. Assume that $Y$ is a Banach space and $\varphi: X^{4} \rightarrow[0, \infty)$ is a mapping such that

$$
\begin{gathered}
\lim _{j \rightarrow \infty} \frac{1}{|C|^{j}} \varphi\left(\left(2 a_{1}\right)^{j} x_{1},\left(2 a_{1}\right)^{j} x_{2},\left(2 b_{1}\right)^{j} y_{1},\left(2 b_{1}\right)^{j} y_{2}\right)=0 \\
x_{1}, x_{2}, y_{1}, y_{2} \in X
\end{gathered}
$$

and

$$
\begin{gathered}
\varphi\left(2 a_{1} x_{1}, 2 a_{1} x_{1}, 2 b_{1} y_{1}, 2 b_{1} y_{1}\right) \leq|C| L \varphi\left(x_{1}, x_{1}, y_{1}, y_{1}\right), \\
x_{1}, y_{1} \in X
\end{gathered}
$$

for an $L \in(0,1)$. If $f: X^{2} \rightarrow Y$ is a function satisfying

$$
f(x, 0)=0=f(0, y), \quad x, y \in X
$$

and

$$
\begin{aligned}
& \| f\left(a_{1}\left(x_{1}+x_{2}\right), b_{1}\left(y_{1}+y_{2}\right)\right)+f\left(a_{2}\left(x_{1}+x_{2}\right), b_{2}\left(y_{1}-y_{2}\right)\right) \\
& \quad+f\left(a_{3}\left(x_{1}-x_{2}\right), b_{3}\left(y_{1}+y_{2}\right)\right)+f\left(a_{4}\left(x_{1}-x_{2}\right), b_{4}\left(y_{1}-y_{2}\right)\right) \\
& \quad-C_{11} f\left(x_{1}, y_{1}\right)-C_{12} f\left(x_{1}, y_{2}\right)-C_{21} f\left(x_{2}, y_{1}\right)-C_{22} f\left(x_{2}, y_{2}\right) \| \\
& \leq \varphi\left(x_{1}, x_{2}, y_{1}, y_{2}\right), \quad x_{1}, x_{2}, y_{1}, y_{2} \in X,
\end{aligned}
$$

then there exists a unique solution $F: X^{2} \rightarrow Y$ of Eq. (1) such that condition (4) holds and

$$
\|f(x, y)-F(x, y)\| \leq \frac{1}{|C|(1-L)} \varphi(x, x, y, y), \quad x, y \in X .
$$

The mapping $F$ is given by

$$
F(x, y)=\lim _{j \rightarrow \infty} \frac{1}{C^{j}} f\left(\left(2 a_{1}\right)^{j} x,\left(2 b_{1}\right)^{j} y\right), \quad x, y \in X .
$$


Proof. Put

$$
\mathcal{G}:=\left\{f: X^{2} \rightarrow Y: f \text { satisfies condition (4) }\right\}
$$

and

$$
\begin{array}{r}
d(g, h):=\inf \{c \in[0, \infty]:\|g(x, y)-h(x, y)\| \\
\leq c \varphi(x, x, y, y), x, y \in X\}, \quad g, h \in \mathcal{G} .
\end{array}
$$

It is a standard verification that the pair $(\mathcal{G}, d)$ is a complete generalized metric space.

Next, define

$$
\operatorname{Tg}(x, y):=\frac{1}{C} g\left(2 a_{1} x, 2 b_{1} y\right), \quad g \in \mathcal{G}, x, y \in X .
$$

We prove that the operator $T: \mathcal{G} \rightarrow \mathcal{G}$ is strictly contractive with the Lipschitz constant $L$. To this end, fix $g, h \in \mathcal{G}, x, y \in X$ and $c_{g, h} \in[0, \infty]$ such that $d(g, h) \leq c_{g, h}$. Then we have

$$
\|g(x, y)-h(x, y)\| \leq c_{g, h} \varphi(x, x, y, y),
$$

whence by $(3)$

$$
\begin{array}{r}
\|T g(x, y)-T h(x, y)\|=\frac{1}{|C|}\left\|g\left(2 a_{1} x, 2 b_{1} y\right)-h\left(2 a_{1} x, 2 b_{1} y\right)\right\| \\
\leq \frac{1}{|C|} c_{g, h} \varphi\left(2 a_{1} x, 2 a_{1} x, 2 b_{1} y, 2 b_{1} y\right) \leq L c_{g, h} \varphi(x, x, y, y) .
\end{array}
$$

Therefore $d(T g, T h) \leq L c_{g, h}$, and consequently $d(T g, T h) \leq L d(g, h)$. This shows that $T$ is strictly contractive with the constant $L$.

Let us next note that by (4) and (5) we get

$$
\|T f(x, y)-f(x, y)\|=\left\|\frac{1}{C} f\left(2 a_{1} x, 2 b_{1} y\right)-f(x, y)\right\| \leq \frac{1}{|C|} \varphi(x, x, y, y),
$$

and therefore

$$
d(T f, f) \leq \frac{1}{|C|}<\infty .
$$

We can now apply Proposition 1 for the space $(\mathcal{G}, d)$, the operator $T, n_{0}=0$ and $x=f$ to deduce that the sequence $\left(T^{j} f\right)_{j \in \mathbb{N}}$ is convergent in $(\mathcal{G}, d)$ and its limit $F$ is a fixed point of $T$.

Thus, we have

$$
F(x, y)=\lim _{j \rightarrow \infty} T^{j} f(x, y)
$$

and

$$
\frac{1}{C} F\left(2 a_{1} x, 2 b_{1} y\right)=F(x, y) .
$$

As one can also prove, by induction, that

$$
T^{j} f(x, y)=\frac{1}{C^{j}} f\left(\left(2 a_{1}\right)^{j} x,\left(2 b_{1}\right)^{j} y\right), \quad j \in \mathbb{N},
$$


we get (7).

Next, note that $f \in \mathcal{G}^{*}$. Proposition 1(iii) and (9) now shows that

$$
d(f, F) \leq \frac{1}{1-L} d(T f, f) \leq \frac{1}{|C|(1-L)},
$$

and thus we obtain (6).

Moreover, it follows from (5) that

$$
\begin{aligned}
& \| \frac{1}{C^{j}} f\left(\left(2 a_{1}\right)^{j} a_{1}\left(x_{1}+x_{2}\right),\left(2 b_{1}\right)^{j} b_{1}\left(y_{1}+y_{2}\right)\right) \\
& \quad+\frac{1}{C^{j}} f\left(\left(2 a_{1}\right)^{j} a_{2}\left(x_{1}+x_{2}\right),\left(2 b_{1}\right)^{j} b_{2}\left(y_{1}-y_{2}\right)\right) \\
& \quad+\frac{1}{C^{j}} f\left(\left(2 a_{1}\right)^{j} a_{3}\left(x_{1}-x_{2}\right),\left(2 b_{1}\right)^{j} b_{3}\left(y_{1}+y_{2}\right)\right) \\
& \quad+\frac{1}{C^{j}} f\left(\left(2 a_{1}\right)^{j} a_{4}\left(x_{1}-x_{2}\right),\left(2 b_{1}\right)^{j} b_{4}\left(y_{1}-y_{2}\right)\right) \\
& \quad-C_{11} \frac{1}{C^{j}} f\left(\left(2 a_{1}\right)^{j} x_{1},\left(2 b_{1}\right)^{j} y_{1}\right)-C_{12} \frac{1}{C^{j}} f\left(\left(2 a_{1}\right)^{j} x_{1},\left(2 b_{1}\right)^{j} y_{2}\right) \\
& \quad-C_{21} \frac{1}{C^{j}} f\left(\left(2 a_{1}\right)^{j} x_{2},\left(2 b_{1}\right)^{j} y_{1}\right)-C_{22} \frac{1}{C^{j}} f\left(\left(2 a_{1}\right)^{j} x_{2},\left(2 b_{1}\right)^{j} y_{2}\right) \| \\
& \leq \\
& \frac{1}{\mid C^{j}} \varphi\left(\left(2 a_{1}\right)^{j} x_{1},\left(2 a_{1}\right)^{j} x_{2},\left(2 b_{1}\right)^{j} y_{1},\left(2 b_{1}\right)^{j} y_{2}\right),
\end{aligned}
$$

for $x_{1}, x_{2}, y_{1}, y_{2} \in X$ and $j \in \mathbb{N}_{0}$. Letting $j \rightarrow \infty$, and using (2) and (7) we deduce hence that the mapping $F: X^{2} \rightarrow Y$ is a solution of functional equation (1).

Let us finally suppose that $F^{\prime}: X^{2} \rightarrow Y$ is a solution of functional equation (1) such that conditions (4) and (6) hold true. Then clearly $F^{\prime}$ fulfills (11), and therefore it is a fixed point of the operator T. Furthermore, from (6) it follows that

$$
d\left(f, F^{\prime}\right) \leq \frac{1}{|C|(1-L)}<\infty
$$

and therefore $F^{\prime} \in \mathcal{G}^{*}$. Proposition 1(ii) now shows that $F^{\prime}=F$, which completes the proof.

Let us mention here that assumption (4) is natural in stability considerations on some types of functional equations, and it also appears in particular cases of (1) (see for instance $[11,21,28]$ ). Whether it can be omitted is an open question.

Theorem 2 with $L:=\frac{1}{|C|}$ and $\varphi: \equiv \varepsilon$ for an $\varepsilon>0$ immediately gives the following result on the classical Hyers-Ulam stability of equation (1), which is a generalization of Theorem 1 in [11]. 
Corollary 3. Assume that $Y$ is a Banach space, $|C|>1$ and $\varepsilon>0$. If $f$ : $X^{2} \rightarrow Y$ is a function such that condition (4) holds and

$$
\begin{aligned}
& \| f\left(a_{1}\left(x_{1}+x_{2}\right), b_{1}\left(y_{1}+y_{2}\right)\right)+f\left(a_{2}\left(x_{1}+x_{2}\right), b_{2}\left(y_{1}-y_{2}\right)\right) \\
& +f\left(a_{3}\left(x_{1}-x_{2}\right), b_{3}\left(y_{1}+y_{2}\right)\right)+f\left(a_{4}\left(x_{1}-x_{2}\right), b_{4}\left(y_{1}-y_{2}\right)\right) \\
& -C_{11} f\left(x_{1}, y_{1}\right)-C_{12} f\left(x_{1}, y_{2}\right)-C_{21} f\left(x_{2}, y_{1}\right)-C_{22} f\left(x_{2}, y_{2}\right) \| \leq \varepsilon, \\
& \quad x_{1}, x_{2}, y_{1}, y_{2} \in X,
\end{aligned}
$$

then there exists a unique solution $F: X^{2} \rightarrow Y$ of Eq. (1) such that condition (4) holds and

$$
\|f(x, y)-F(x, y)\| \leq \frac{\varepsilon}{|C|-1}, \quad x, y \in X .
$$

The mapping $F$ is given by (7).

\section{Some Consequences}

Now, we present some further consequences of Theorem 2. Namely, we apply it to get some Hyers-Ulam stability results for three functional equations studied in $[21,28,29]$. These equations are connected with the two famous functional equations:

- the Cauchy equation

$$
a(x+y)=a(x)+a(y)
$$

and

- the Jordan-von Neumann (quadratic) equation

$$
q(x+y)+q(x-y)=2 q(x)+2 q(y) .
$$

Let us start with the functional equation

$$
\begin{gathered}
f\left(x_{1}+x_{2}, y_{1}+y_{2}\right)+f\left(x_{1}-x_{2}, y_{1}-y_{2}\right) \\
=2 f\left(x_{1}, y_{1}\right)+2 f\left(x_{1}, y_{2}\right) .
\end{gathered}
$$

Let us here mention that the stability of this equation was very recently studied in $[21]$.

Corollary 4. Assume that $Y$ is a Banach space and $\varphi: X^{4} \rightarrow[0, \infty)$ is a mapping such that

$$
\lim _{j \rightarrow \infty} \frac{1}{4^{j}} \varphi\left(2^{j} x_{1}, 2^{j} x_{2}, 2^{j} y_{1}, 2^{j} y_{2}\right)=0, \quad x_{1}, x_{2}, y_{1}, y_{2} \in X
$$

and

$$
\varphi\left(2 x_{1}, 2 x_{1}, 2 y_{1}, 2 y_{1}\right) \leq 4 L \varphi\left(x_{1}, x_{1}, y_{1}, y_{1}\right), \quad x_{1}, y_{1} \in X
$$


for an $L \in(0,1)$. If $f: X^{2} \rightarrow Y$ is a function such that condition (4) holds and

$$
\begin{aligned}
& \left\|f\left(x_{1}+x_{2}, y_{1}+y_{2}\right)+f\left(x_{1}-x_{2}, y_{1}-y_{2}\right)-2 f\left(x_{1}, y_{1}\right)-2 f\left(x_{1}, y_{2}\right)\right\| \\
& \leq \varphi\left(x_{1}, x_{2}, y_{1}, y_{2}\right), \quad x_{1}, x_{2}, y_{1}, y_{2} \in X,
\end{aligned}
$$

then there exists a unique solution $F: X^{2} \rightarrow Y$ of Eq. (13) fullfiling (4) and

$$
\|f(x, y)-F(x, y)\| \leq \frac{1}{4(1-L)} \varphi(x, x, y, y), \quad x, y \in X .
$$

The mapping $F$ is given by

$$
F(x, y)=\lim _{j \rightarrow \infty} \frac{1}{4^{j}} f\left(2^{j} x, 2^{j} y\right), \quad x, y \in X .
$$

Proof. It suffices to apply Theorem 2 with $a_{1}=b_{1}=a_{4}=b_{4}=1, a_{2}=b_{2}=$ $a_{3}=b_{3}=0, C_{1,1}=C_{1,2}=2$ and $C_{2,1}=C_{2,2}=0$.

Corollary 4 with $L:=\frac{1}{4}$ and $\varphi: \equiv \varepsilon$ for an $\varepsilon>0$ immediately gives the following result on the classical Hyers-Ulam stability of equation (13).

Corollary 5. Assume that $Y$ is a Banach space and $\varepsilon>0$. If $f: X^{2} \rightarrow Y$ is a function such that (4) holds and

$$
\begin{aligned}
& \left\|f\left(x_{1}+x_{2}, y_{1}+y_{2}\right)+f\left(x_{1}-x_{2}, y_{1}-y_{2}\right)-2 f\left(x_{1}, y_{1}\right)-2 f\left(x_{1}, y_{2}\right)\right\| \\
& \leq \varepsilon, \quad x_{1}, x_{2}, y_{1}, y_{2} \in X,
\end{aligned}
$$

then there exists a unique solution $F: X^{2} \rightarrow Y$ of Eq. (13) fullfiling (4) and

$$
\|f(x, y)-F(x, y)\| \leq \frac{\varepsilon}{3}, \quad x, y \in X .
$$

The mapping $F$ is given by (14).

Next, consider the case $a_{1}=b_{1}=\ldots=a_{4}=b_{4}=1$ and $C_{11}=C_{12}=$ $C_{21}=C_{22}=4$. Then from (1) we get the following functional equation

$$
\begin{aligned}
& f\left(x_{1}+x_{2}, y_{1}+y_{2}\right)+f\left(x_{1}+x_{2}, y_{1}-y_{2}\right) \\
& \quad+f\left(x_{1}-x_{2}, y_{1}+y_{2}\right)+f\left(x_{1}-x_{2}, y_{1}-y_{2}\right) \\
& =4 f\left(x_{1}, y_{1}\right)+4 f\left(x_{1}, y_{2}\right)+4 f\left(x_{2}, y_{1}\right)+4 f\left(x_{2}, y_{2}\right),
\end{aligned}
$$

which was introduced and studied in [28]. Let us also mention (see [28]) that this equation characterizes the so-called bi-quadratic mappings, i.e., functions $f: X^{2} \rightarrow Y$ which are quadratic in each of their arguments. Its stability was already considered in $[11,28]$. Now, we have the following. 
Corollary 6. Assume that $Y$ is a Banach space and $\varphi: X^{4} \rightarrow[0, \infty)$ is a mapping such that

$$
\lim _{j \rightarrow \infty} \frac{1}{16^{j}} \varphi\left(2^{j} x_{1}, 2^{j} x_{2}, 2^{j} y_{1}, 2^{j} y_{2}\right)=0, \quad x_{1}, x_{2}, y_{1}, y_{2} \in X
$$

and

$$
\varphi\left(2 x_{1}, 2 x_{1}, 2 y_{1}, 2 y_{1}\right) \leq 16 L \varphi\left(x_{1}, x_{1}, y_{1}, y_{1}\right), \quad x_{1}, y_{1} \in X
$$

for an $L \in(0,1)$. If $f: X^{2} \rightarrow Y$ is a function satisfying condition (4) and

$$
\begin{aligned}
& \| f\left(x_{1}+x_{2}, y_{1}+y_{2}\right)+f\left(x_{1}+x_{2}, y_{1}-y_{2}\right) \\
& \quad+f\left(x_{1}-x_{2}, y_{1}+y_{2}\right)+f\left(x_{1}-x_{2}, y_{1}-y_{2}\right) \\
& \quad-4 f\left(x_{1}, y_{1}\right)-4 f\left(x_{1}, y_{2}\right)-4 f\left(x_{2}, y_{1}\right)-4 f\left(x_{2}, y_{2}\right) \| \\
& \leq \varphi\left(x_{1}, x_{2}, y_{1}, y_{2}\right), \quad x_{1}, x_{2}, y_{1}, y_{2} \in X,
\end{aligned}
$$

then there exists a unique solution $F: X^{2} \rightarrow Y$ of Eq. (15) such that condition (4) holds and

$$
\|f(x, y)-F(x, y)\| \leq \frac{1}{16(1-L)} \varphi(x, x, y, y), \quad x, y \in X .
$$

The mapping $F$ is given by

$$
F(x, y)=\lim _{j \rightarrow \infty} \frac{1}{16^{j}} f\left(2^{j} x, 2^{j} y\right), \quad x, y \in X .
$$

Proof. It suffices to apply Theorem 2 with $a_{1}=b_{1}=\ldots=a_{4}=b_{4}=1$ and $C_{11}=C_{12}=C_{21}=C_{22}=4$.

From Corollary 6 with $L:=\frac{1}{16}$ and $\varphi: \equiv \varepsilon$ for an $\varepsilon>0$ we immediately obtain the following result on the classical Hyers-Ulam stability of equation (15).

Corollary 7. Assume that $Y$ is a Banach space and $\varepsilon>0$. If $f: X^{2} \rightarrow Y$ is a function such that (4) holds and

$$
\begin{aligned}
& \| f\left(x_{1}+x_{2}, y_{1}+y_{2}\right)+f\left(x_{1}+x_{2}, y_{1}-y_{2}\right) \\
& \quad+f\left(x_{1}-x_{2}, y_{1}+y_{2}\right)+f\left(x_{1}-x_{2}, y_{1}-y_{2}\right) \\
& \quad-4 f\left(x_{1}, y_{1}\right)-4 f\left(x_{1}, y_{2}\right)-4 f\left(x_{2}, y_{1}\right)-4 f\left(x_{2}, y_{2}\right) \| \\
& \leq \varepsilon, \quad x_{1}, x_{2}, y_{1}, y_{2} \in X,
\end{aligned}
$$

then there exists a unique solution $F: X^{2} \rightarrow Y$ of Eq. (15) fullfiling (4) and

$$
\|f(x, y)-F(x, y)\| \leq \frac{\varepsilon}{15}, \quad x, y \in X .
$$


The mapping $F$ is given by (16).

A more general case of equation (1), i.e. the functional equation

$$
\begin{aligned}
& f\left(x_{1}+x_{2}, y_{1}+y_{2}\right)+f\left(x_{1}+x_{2}, y_{1}-y_{2}\right) \\
& \quad+f\left(x_{1}-x_{2}, y_{1}+y_{2}\right)+f\left(x_{1}-x_{2}, y_{1}-y_{2}\right) \\
& =C_{11} f\left(x_{1}, y_{1}\right)+C_{12} f\left(x_{1}, y_{2}\right)+C_{21} f\left(x_{2}, y_{1}\right)+C_{22} f\left(x_{2}, y_{2}\right),
\end{aligned}
$$

with $C_{11}, C_{12}, C_{21}, C_{22} \geq 0$, was very recently investigated in [17], where its characterizations and representations of set-valued solutions are obtained. As for the generalized Hyers-Ulam stability of Eq. (17), we have the following.

Corollary 8. Assume that $Y$ is a Banach space and $\varphi: X^{4} \rightarrow[0, \infty)$ is a mapping such that

$$
\lim _{j \rightarrow \infty} \frac{1}{|C|^{j}} \varphi\left(2^{j} x_{1}, 2^{j} x_{2}, 2^{j} y_{1}, 2^{j} y_{2}\right)=0, \quad x_{1}, x_{2}, y_{1}, y_{2} \in X
$$

and

$$
\varphi\left(2 x_{1}, 2 x_{1}, 2 y_{1}, 2 y_{1}\right) \leq|C| L \varphi\left(x_{1}, x_{1}, y_{1}, y_{1}\right), \quad x_{1}, y_{1} \in X
$$

for an $L \in(0,1)$. If $f: X^{2} \rightarrow Y$ is a function satisfying condition (4) and

$$
\begin{aligned}
& \| f\left(x_{1}+x_{2}, y_{1}+y_{2}\right)+f\left(x_{1}+x_{2}, y_{1}-y_{2}\right) \\
& \quad+f\left(x_{1}-x_{2}, y_{1}+y_{2}\right)+f\left(x_{1}-x_{2}, y_{1}-y_{2}\right) \\
& \quad-C_{11} f\left(x_{1}, y_{1}\right)-C_{12} f\left(x_{1}, y_{2}\right)-C_{21} f\left(x_{2}, y_{1}\right)-C_{22} f\left(x_{2}, y_{2}\right) \| \\
& \leq \varphi\left(x_{1}, x_{2}, y_{1}, y_{2}\right), \quad x_{1}, x_{2}, y_{1}, y_{2} \in X,
\end{aligned}
$$

then there exists a unique solution $F: X^{2} \rightarrow Y$ of Eq. (17) such that conditions (4) and (6) hold. The mapping $F$ is given by

$$
F(x, y)=\lim _{j \rightarrow \infty} \frac{1}{C^{j}} f\left(2^{j} x, 2^{j} y\right), \quad x, y \in X .
$$

Proof. It suffices to apply Theorem 2 with $a_{1}=b_{1}=\ldots=a_{4}=b_{4}=1$.

Using Corollary 8 with $L:=\frac{1}{|C|}$ and $\varphi: \equiv \varepsilon$ for an $\varepsilon>0$ we immediately get the following outcome on the classical Hyers-Ulam stability of equation (17). 
Corollary 9. Assume that $Y$ is a Banach space, $|C|>1$ and $\varepsilon>0$. If $f$ : $X^{2} \rightarrow Y$ is a function such that (4) holds and

$$
\begin{aligned}
& \| f\left(x_{1}+x_{2}, y_{1}+y_{2}\right)+f\left(x_{1}+x_{2}, y_{1}-y_{2}\right) \\
& \quad+f\left(x_{1}-x_{2}, y_{1}+y_{2}\right)+f\left(x_{1}-x_{2}, y_{1}-y_{2}\right) \\
& \quad-C_{11} f\left(x_{1}, y_{1}\right)-C_{12} f\left(x_{1}, y_{2}\right)-C_{21} f\left(x_{2}, y_{1}\right)-C_{22} f\left(x_{2}, y_{2}\right) \| \\
& \leq \varepsilon, \quad x_{1}, x_{2}, y_{1}, y_{2} \in X,
\end{aligned}
$$

then there exists a unique solution $F: X^{2} \rightarrow Y$ of Eq. (17) fullfiling conditions (4) and (12). The mapping $F$ is given by (18).

Finally, we deal with the Hyers-Ulam stability of the following functional equation

$$
\begin{aligned}
& f\left(x_{1}+x_{2}, y_{1}+y_{2}\right)+f\left(x_{1}+x_{2}, y_{1}-y_{2}\right) \\
& =2 f\left(x_{1}, y_{1}\right)+2 f\left(x_{1}, y_{2}\right)+2 f\left(x_{2}, y_{1}\right)+2 f\left(x_{2}, y_{2}\right),
\end{aligned}
$$

which was introduced and studied in [29].

Corollary 10. Assume that $Y$ is a Banach space and $\varphi: X^{4} \rightarrow[0, \infty)$ is a mapping such that

$$
\lim _{j \rightarrow \infty} \frac{1}{8^{j}} \varphi\left(2^{j} x_{1}, 2^{j} x_{2}, 2^{j} y_{1}, 2^{j} y_{2}\right)=0, \quad x_{1}, x_{2}, y_{1}, y_{2} \in X
$$

and

$$
\varphi\left(2 x_{1}, 2 x_{1}, 2 y_{1}, 2 y_{1}\right) \leq 8 L \varphi\left(x_{1}, x_{1}, y_{1}, y_{1}\right), \quad x_{1}, y_{1} \in X
$$

for an $L \in(0,1)$. If $f: X^{2} \rightarrow Y$ is a function satisfying condition (4) and

$$
\begin{aligned}
& \| f\left(x_{1}+x_{2}, y_{1}+y_{2}\right)+f\left(x_{1}+x_{2}, y_{1}-y_{2}\right) \\
& \quad-2 f\left(x_{1}, y_{1}\right)-2 f\left(x_{1}, y_{2}\right)-2 f\left(x_{2}, y_{1}\right)-2 f\left(x_{2}, y_{2}\right) \| \\
& \leq \varphi\left(x_{1}, x_{2}, y_{1}, y_{2}\right), \quad x_{1}, x_{2}, y_{1}, y_{2} \in X,
\end{aligned}
$$

then there exists a unique solution $F: X^{2} \rightarrow Y$ of equation (19) such that condition (4) holds and

$$
\|f(x, y)-F(x, y)\| \leq \frac{1}{8(1-L)} \varphi(x, x, y, y), \quad x, y \in X .
$$

The mapping $F$ is given by

$$
F(x, y)=\lim _{j \rightarrow \infty} \frac{1}{8^{j}} f\left(2^{j} x, 2^{j} y\right), \quad x, y \in X .
$$


Proof. It suffices to apply Theorem 2 with $a_{1}=b_{1}=a_{2}=b_{2}=1, a_{3}=b_{3}=$ $a_{4}=b_{4}=0$ and $C_{11}=C_{12}=C_{21}=C_{22}=2$.

By Corollary 10 with $L:=\frac{1}{8}$ and $\varphi: \equiv \varepsilon$ for an $\varepsilon>0$ we get the following result on the Hyers-Ulam stability of Eq. (19).

Corollary 11. Assume that $Y$ is a Banach space and $\varepsilon>0$. If $f: X^{2} \rightarrow Y$ is a function such that (4) holds and

$$
\begin{aligned}
& \| f\left(x_{1}+x_{2}, y_{1}+y_{2}\right)+f\left(x_{1}+x_{2}, y_{1}-y_{2}\right) \\
& \quad-2 f\left(x_{1}, y_{1}\right)-2 f\left(x_{1}, y_{2}\right)-2 f\left(x_{2}, y_{1}\right)-2 f\left(x_{2}, y_{2}\right) \| \\
& \leq \varepsilon, \quad x_{1}, x_{2}, y_{1}, y_{2} \in X,
\end{aligned}
$$

then there exists a unique solution $F: X^{2} \rightarrow Y$ of equation (19) fullfiling (4) and

$$
\|f(x, y)-F(x, y)\| \leq \frac{\varepsilon}{7}, \quad x, y \in X
$$

The mapping $F$ is given by (20).

Data availability Data sharing not applicable to this article as no datasets were generated or analysed during the current study.

\section{Declarations}

Conflict of interest The author declares that he has no conflict of interest.

Open Access. This article is licensed under a Creative Commons Attribution 4.0 International License, which permits use, sharing, adaptation, distribution and reproduction in any medium or format, as long as you give appropriate credit to the original author(s) and the source, provide a link to the Creative Commons licence, and indicate if changes were made. The images or other third party material in this article are included in the article's Creative Commons licence, unless indicated otherwise in a credit line to the material. If material is not included in the article's Creative Commons licence and your intended use is not permitted by statutory regulation or exceeds the permitted use, you will need to obtain permission directly from the copyright holder. To view a copy of this licence, visit http://creativecommons. org/licenses/by/4.0/.

\section{References}

[1] Anderson, D.R., Onitsuka, M.: Best constant for Hyers-Ulam stability of secondorder $h$-difference equations with constant coefficients. Results Math. 74, 151 (2019)

[2] Baias, A.R., Popa, D., Raşa, I.: Ulam stability of a successive approximation equation. J. Fixed Point Theory Appl. 22, 41 (2020) 
[3] Becker, O., Lubotzky, A., Thom, A.: Stability and invariant random subgroups. Duke Math. J. 168, 2207-2234 (2019)

[4] Bourgin, D.G.: Classes of transformations and bordering transformations. Bull. Am. Math. Soc. 57, 223-237 (1951)

[5] Brillouët-Belluot, N., Brzdȩk, J., Ciepliński, K.: On some recent developments in Ulam's type stability. Abstr. Appl. Anal. 2012, 716936 (2012)

[6] Brzdȩk, J., Cădariu, L., Ciepliński, K.: Fixed point theory and the Ulam stability. J. Funct. Spaces 2014, 829419 (2014)

[7] Brzdȩk, J., Popa, D., Raşa, I., Xu, B.: Ulam Stability of Operators. Academic Press, London (2018)

[8] Castro, L.P., Simões, A.M.: Hyers-Ulam-Rassias stability of nonlinear integral equations through the Bielecki metric. Math. Methods Appl. Sci. 41, 7367-7383 (2018)

[9] Cheng, L., Dong, Y.: A note on the stability of nonsurjective $\varepsilon$-isometries of Banach spaces. Proc. Am. Math. Soc. 148, 4837-4844 (2020)

[10] Ciepliński, K.: Applications of fixed point theorems to the Hyers-Ulam stability of functional equations - a survey. Ann. Funct. Anal. 3, 151-164 (2012)

[11] Ciepliński, K.: Ulam stability of a functional equation in various normed spaces. Symmetry 12, 1119 (2020)

[12] Ciepliński, K.: On Ulam stability of a functional equation. Results Math. 75, 151 (2020)

[13] De Chiffre, M., Glebsky, L., Lubotzky, A., Thom, A.: Stability, cohomology vanishing, and nonapproximable groups. Forum Math. Sigma 8, e18 (2020)

[14] de Oliveira, E.C., Sousa, J.V.C.: Ulam-Hyers-Rassias stability for a class of fractional integro-differential equations. Results Math. 73, 111 (2018)

[15] Diaz, J.B., Margolis, B.: A fixed point theorem of the alternative for contractions on a generalized complete metric space. Bull. Am. Math. Soc. 74, 305-309 (1968)

[16] Eilers, S., Shulman, T., Sørensen, A.P.W.: $C^{*}$-stability of discrete groups. Adv. Math. 373, 107324 (2020)

[17] EL-Fassi, I., El-Hady, E., Nikodem, K.: On set-valued solutions of a generalized bi-quadratic functional equation. Results Math. 75, 89 (2020)

[18] Farah, I.: All automorphisms of the Calkin algebra are inner. Ann. Math. 2(173), 619-661 (2011)

[19] Fukutaka, R., Onitsuka, M.: Best constant for Ulam stability of Hill's equations. Bull. Sci. Math. 163, 102888 (2020)

[20] Guan, Y., Fečkan, M., Wang, J.: Periodic solutions and Hyers-Ulam stability of atmospheric Ekman flows. Discrete Contin. Dyn. Syst. (2021). https://doi.org/ 10.3934/dcds.2020313

[21] Hwang, I., Park, C.: Ulam stability of an additive-quadratic functional equation in Banach spaces. J. Math. Inequal. 14, 421-436 (2020)

[22] Hyers, D.H.: On the stability of the linear functional equation. Proc. Natl. Acad. Sci. U.S.A. 27, 222-224 (1941)

[23] Jung, S.-M.: Hyers-Ulam-Rassias Stability of Functional Equations in Nonlinear Analysis. Springer, New York (2011) 
[24] Kochanek, T.: Stability of vector measures and twisted sums of Banach spaces. J. Funct. Anal. 264, 2416-2456 (2013)

[25] McKenney, P., Vignati, A.: Ulam stability for some classes of $C^{*}$-algebras. Proc. R. Soc. Edinb. Sect. A 149, 45-59 (2019)

[26] Monod, N.: An invitation to bounded cohomology.In: International Congress of Mathematicians, vol. II, pp. 1183-1211. European Mathematical Society, Zürich (2006)

[27] Páles, Z.: Generalized stability of the Cauchy functional equation. Aequationes Math. 56, 222-232 (1998)

[28] Park, W.-G., Bae, J.-H.: On a bi-quadratic functional equation and its stability. Nonlinear Anal. 62, 643-654 (2005)

[29] Park, W.-G., Bae, J.-H., Chung, B.-H.: On an additive-quadratic functional equation and its stability. J. Appl. Math. Comput. 18, 563-572 (2005)

[30] Sousa, J.V.C., de Oliveira, E.C., Kucche, K.D.: On the fractional functional differential equation with abstract Volterra operator. Bull. Braz. Math. Soc. N. S. 50(4), 803-822 (2019)

[31] Székelyhidi, L.: Note on a stability theorem. Can. Math. Bull. 25, 500-501 (1982)

[32] Tabor, J., Tabor, J.: General stability of functional equations of linear type. J. Math. Anal. Appl. 328, 192-200 (2007)

Krzysztof Ciepliński

AGH University of Science and Technology, Faculty of Applied Mathematics

Mickiewicza 30

30-059 Kraków

Poland

e-mail: cieplin@agh.edu.pl

Received: October 26, 2020.

Accepted: February 26, 2021.

Publisher's Note Springer Nature remains neutral with regard to jurisdictional claims in published maps and institutional affiliations. 